Marquette University

e-Publications@Marquette

$2-1-2010$

Defining the Structural Consequences of Mechanism-Based Inactivation of Mammalian Cytochrome P450 2B4 Using Resonance Raman Spectroscopy

Piotr J. Mak

Marquette University, piotr.mak@marquette.edu

Haoming Zhang

University of Michigan - Ann Arbor

Paul F. Hollenberg

University of Michigan - Ann Arbor

James R. Kincaid

Marquette University, james.kincaid@marquette.edu

Accepted version. Journal of the American Chemical Society, Vol. 132, No. 5 (February 2010):

1494-1495. DOI. (C) 2010 American Chemical Society. Used with permission. 


\title{
Defining the Structural \\ Consequences of Mechanism-Based \\ Inactivation of Mammalian \\ Cytochrome P450 2B4 Using \\ Resonance Raman Spectroscopy
}

\author{
Piotr J. Mak \\ Department of Chemistry, Marquette University, \\ Milwaukee, WI \\ Haoming Zhang \\ Department of Pharmacology, University of Michigan, \\ Ann Arbor, MI \\ Paul F. Hollenberg \\ Department of Pharmacology, University of Michigan, \\ Ann Arbor, MI \\ James R. Kincaid \\ Department of Chemistry, Marquette University, \\ Milwaukee, WI
}




\section{Abstract}
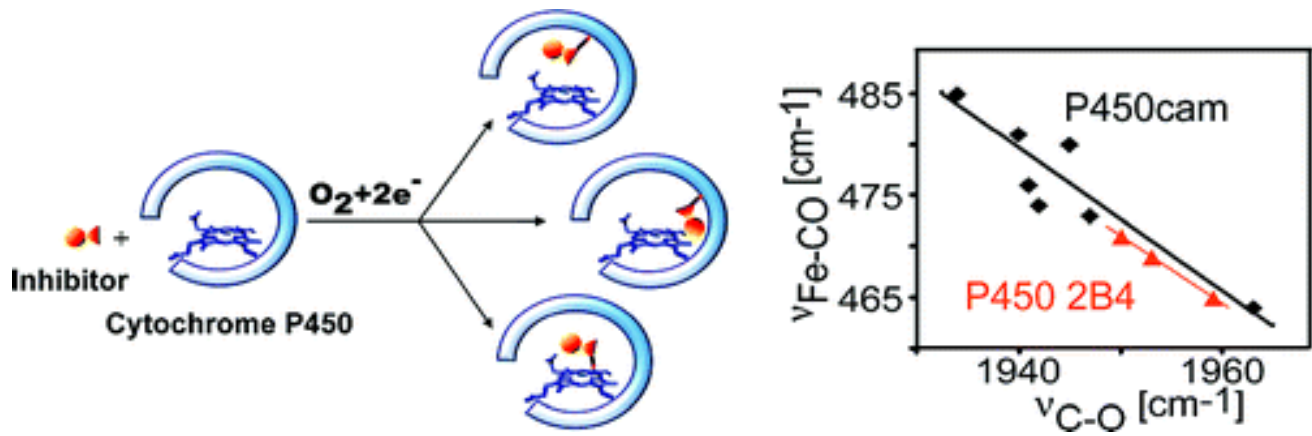

In view of the potent oxidizing strength of cytochrome P450 intermediates, it is not surprising that certain substrates can give rise to reactive species capable of attacking the heme or critical distal-pocket protein residues to irreversibly modify the enzyme in a process known as mechanism-based (MB) inactivation, a result that can have serious physiological consequences leading to adverse drug-drug interactions and toxicity. While methods exist to document the attachment of these substrate fragments, it is more difficult to gain insight into the structural basis for the altered functional properties of these modified enzymes. In response to this pressing need to better understand MB inhibition, we here report the first application of resonance Raman spectroscopy to study the inactivation of a truncated form of mammalian CYP2B4 by the acetylenic inhibitor 4-(tert-butyl)phenylacetylene, whose activated form is known to attach to the distal-pocket T302 residue of CYP2B4.

Membrane-bound human cytochromes P450, which are responsible for catalyzing the metabolism of pharmaceuticals or other xenobiotics, ${ }^{1}$ proceed through a complex cycle involving the sequential delivery of two electrons to a heme-bound dioxygen complex, effecting the splitting of the $\mathrm{O}-\mathrm{O}$ bond to generate a potent oxygenating intermediate capable of inserting a single oxygen atom into the bound substrates, the nature of the putative intermediate generally being formulated as a ferryl heme $n$-cation similar to the Compound I species in the enzymatic cycles of the heme peroxidases. ${ }^{1}$ In view of the impressive oxidizing strength of this species, it is not surprising that certain substrates give rise to reactive intermediates capable of attacking the heme or critical distal-pocket protein residues to irreversibly modify the enzyme in a process known as mechanismbased (MB) inactivation. ${ }^{2}$ Some of the common compounds that fall into the category of MB inactivators are acetylenes, organosulfur compounds, arylamines, and others. ${ }^{2}$ 
Obviously, inasmuch as such irreversible inactivation can have profound physiological consequences leading to adverse drug-drug interactions or toxicity, it is important to gain structural insight into the altered functional behavior of these modified P450s. One of the most powerful techniques available for this purpose is resonance Raman (RR) spectroscopy, which is able to provide critical information about the heme active-site structure, including reliable documentation of the iron oxidation and spin states ${ }^{3}$ and the disposition of bound exogenous ligands, permitting characterization of unstable intermediates such as the oxy, peroxo, and hydroperoxo intermediates that arise in the $\mathrm{P} 450$ cycle. $^{3-6}$ In response to the pressing need to better understand MB inhibition, we here report the first application of $R R$ to study the inactivation of a truncated form of mammalian CYP2B4 by the acetylenic inhibitor 4-(tert-butyl)phenylacetylene (BPA), whose activated form is known to attach to the distal-pocket T302 residue of CYP2B4 (Figure S1 in the Supporting Information). ${ }^{7}$

The high-frequency RR spectra of the wild-type substrate-free ferric enzyme (WT 2B4dH SF) and its adduct with the prototypical substrate benzphetamine (WT 2B4dH BZ) are shown in Figure 1. The spectrum of the SF sample (trace $A$ ) exhibits the oxidation-state marker mode $v_{4}$ at $1372 \mathrm{~cm}^{-1}$ and the $v_{3}$ and $v_{2}$ spin-state markers at 1502 and $1583 \mathrm{~cm}^{-1}$, respectively, confirming the presence of a ferric low-spin state. ${ }^{3,8}$ The addition of BZ (trace B) causes partial spin-state conversion (seen as an increase in the intensity of the high-spin $v_{3}$ mode at $1487 \mathrm{~cm}^{-1}$ ) associated with disruption of the distal-pocket water cluster, entirely consistent with the RR data previously reported for full-length ferric substrate-free and BZ-bound cytochrome 2B4. ${ }^{9}$ The spectrum of the BPA-modified $2 \mathrm{~B} 4 \mathrm{dH}$ without added substrate (modified 2B4dH SF, trace C) exhibits a spectral pattern essentially identical to that of the WT sample, indicating that the enzyme modification has no substantial impact on the resting-state heme structure. The first interesting observation is that addition of substrate (BZ) to BPA-modified 2B4dH causes no changes in the heme spin state or macrocyclic core structure, as judged by the virtually identical RR spectra (traces $C$ and D), the lack of such changes for the modified form being consistent with the blocking of substrate access by the attached BPA fragment. ${ }^{7}$ As shown in Figure S2, the low-frequency RR spectral data also confirm the lack of significant changes associated 
with the attached fragment and the apparent blocking of $\mathrm{BZ}$ access to the active site.

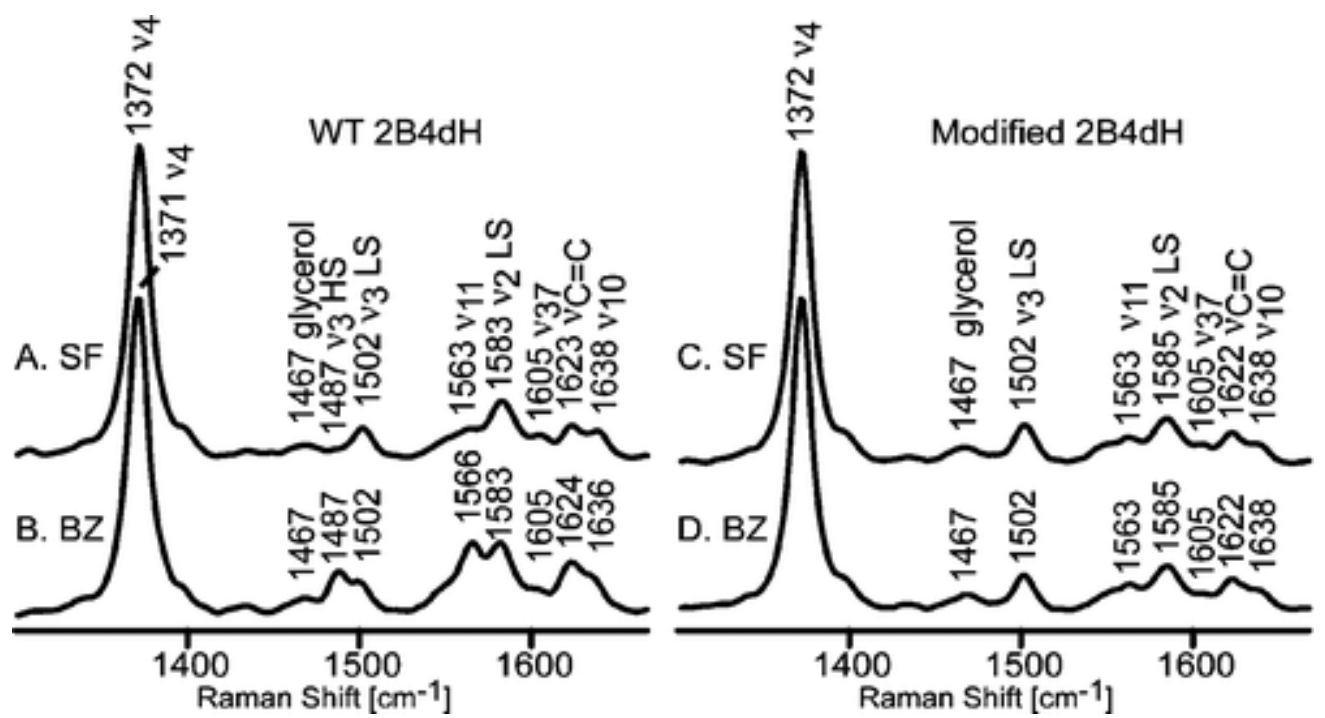

Figure 1. High-frequency resonance Raman spectra of $(A, B)$ ferric wild-type cytochrome 2B4 (WT 2B4dH) and (C, D) modified cytochrome 2B4 (modified 2B4dH): $(A, C)$ substrate-free (SF); (B, D) in the presence of benzphetamine (BZ). All of the spectra were measured with the $406 \mathrm{~nm}$ excitation line at room temperature. Spectra normalized to the $\mathrm{v}_{4}$ mode at $(A, C, D) 1372$ and (B) $1371 \mathrm{~cm}^{-1}$.

It is also of obvious importance to interrogate the ligated forms of this modified protein. While the oxy and reduced oxy intermediates are generally quite unstable ${ }^{1}$ the stable ferrous $\mathrm{CO}$ form is readily characterized by RR measurements. This form mimics the physiologically relevant oxy form, providing important information about the heme moiety and distal side-pocket structure that can affect ligand-protein interactions. ${ }^{8-16}$ Figure 2 shows the low-frequency RR spectra of the $\mathrm{CO}$ adducts, where the $\mathrm{v}(\mathrm{Fe}-\mathrm{CO})$ stretching and $\delta(\mathrm{Fe}-\mathrm{C}-\mathrm{O})$ bending modes are observed, and the high-frequency region containing the $\mathrm{v}(\mathrm{C}-\mathrm{O})$ mode. The spectrum of WT 2B4dH SF exhibits a strong $v(\mathrm{Fe}-\mathrm{CO})$ stretching mode at $471 \mathrm{~cm}^{-1}$ and a $\delta\left(\mathrm{Fe}-\mathrm{C}-\mathrm{O}\right.$ ) bending mode at $558 \mathrm{~cm}^{-1}$ (trace $\mathrm{A}$ ), with the corresponding $\mathrm{v}(\mathrm{C}-\mathrm{O})$ mode occurring at $1950 \mathrm{~cm}^{-1}$. Addition of $\mathrm{BZ}$ causes a small $2 \mathrm{~cm}^{-1}$ downshift of the $\mathrm{v}(\mathrm{Fe}-\mathrm{CO}$ ) mode (trace $\mathrm{B}$ ), the magnitude of the shift being similar to those observed previously in full-length $2 \mathrm{~B} 4 ;^{9}$ the $\mathrm{v}(\mathrm{C}-\mathrm{O})$ mode shifts upward slightly to 1953 $\mathrm{cm}^{-1}$. Of greatest significance is the relatively large $6 \mathrm{~cm}^{-1}$ downshift of the Fe-CO mode observed for modified 2B4 SF (trace $\mathrm{C}$ ), with the corresponding $\mathrm{v}(\mathrm{C}-\mathrm{O})$ stretching mode being upshifted by $9 \mathrm{~cm}^{-1}$ to 
$1959 \mathrm{~cm}^{-1}$; both shifts imply a substantial decrease in distal hemepocket polarity and weakening of any possible $\mathrm{H}$-bonding interactions. These data provide the first direct spectroscopic evidence that the fragment is positioned in such a way as to impact the disposition of bound exogenous ligands, which is presumably also relevant for the dioxygen adduct and the key peroxo and hydroperoxo fragments. Finally, the addition of BZ to the modified protein sample (trace D) does not affect the Fe-CO mode (the difference pattern for the spectra of the modified protein with and without BZ is featureless), a result that further supports the conclusion drawn from study of the ferric forms (Figure 1) that the attached BPA fragment blocks the entrance of substrate into the heme cavity.

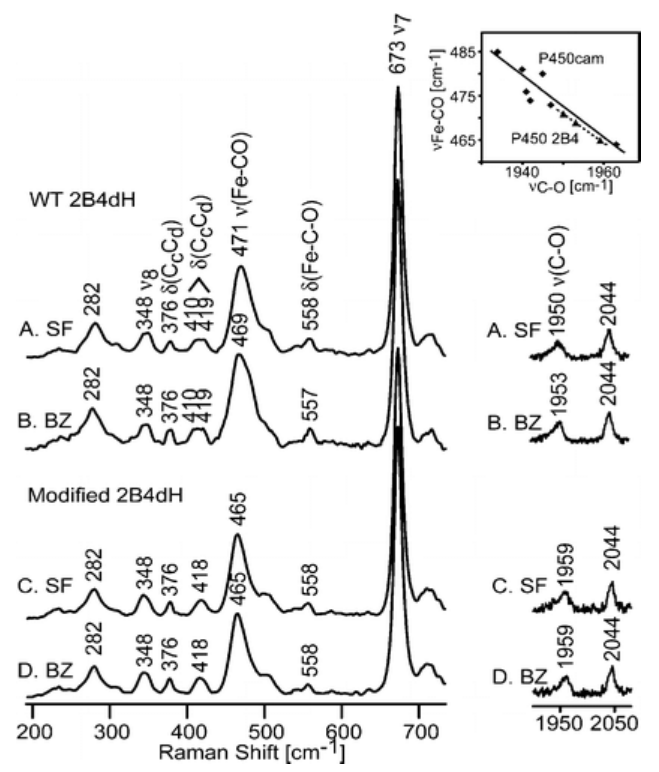

Figure 2. RR spectra of ferrous $C O$ adducts of $(A, B)$ WT and $(C, D)$ modified $2 B 4 d H$ : $(A, C)$ substrate-free; $(B, D)$ in the presence of $B Z$. The spectra were measured with $442 \mathrm{~nm}$ excitation at room temperature. The inset shows the inverse correlation between $\mathrm{v}(\mathrm{C}-\mathrm{O})$ and $\mathrm{v}(\mathrm{Fe}-\mathrm{CO})$ (diamonds, $\mathrm{P} 450 \mathrm{cam} ;{ }^{8,13-16}$ triangles, $\left.\mathrm{P} 4502 \mathrm{~B} 4\right)$.

In addition to these changes in the $\mathrm{Fe}-\mathrm{C}-\mathrm{O}$ fragment, careful spectroscopic interrogation of these samples revealed additional changes in the "vinyl bending" modes. In the case of WT 2B4dH (trace A) there are two vinyl bending modes, at 410 and $419 \mathrm{~cm}^{-1}$, whereas in the spectrum of the modified protein (trace $\mathrm{C}$ ), there is only one vinyl bending mode at $418 \mathrm{~cm}^{-1}$, the lower-frequency mode having apparently shifted to a position near the higher one. Similar behavior was seen in the high-frequency region, where $\mathrm{v}(\mathrm{C}=\mathrm{C})$ stretching modes are observed: in the spectra of the modified protein, the lower- 
frequency mode at $1620 \mathrm{~cm}^{-1}$ loses intensity while the mode at 1634 $\mathrm{cm}^{-1}$ gains intensity relative to the spectra of the WT protein (Figure S3). The lower-frequency vinyl bending and stretching modes are commonly associated with the in-plane configuration of vinyl groups, while the higher-frequency bands are associated with out-of-plane orientations. ${ }^{17}$ This demonstrated ability to document changes in these vinyl bending and stretching modes is therefore of special importance, as the orientation of the vinyl groups with respect to the plane of the heme macrocyle has been suggested to carry functional significance by modifying the heme reduction potential and affinity for axial ligands. ${ }^{18,19}$

The changes seen in the behavior of the modes of the $\mathrm{Fe}-\mathrm{C}-\mathrm{O}$ fragment are useful indicators of distal-pocket structure. ${ }^{10-16}$ The $\mathrm{v}(\mathrm{Fe}-\mathrm{CO})$ and $\mathrm{v}(\mathrm{C}-\mathrm{O})$ stretching frequencies in heme proteins usually follow an inverse correlation that reflects $\mathrm{Fe}-\mathrm{CO}$ back-bonding, as shown in the inset of Figure 2.10-16 The magnitudes of such shifts are influenced by the strength of the trans-proximal ligand bond and the polarity of the distal-pocket environment, i.e., positive charge (including $\mathrm{H}$ bonding) increases the $\mathrm{v}(\mathrm{Fe}-\mathrm{CO})$ frequencies and decreases the $\mathrm{v}(\mathrm{C}-\mathrm{O})$ frequencies along the correlation, while its elimination has the opposite effect. ${ }^{10-16}$ The comparison of the newly obtained data for the $\mathrm{CO}$ adducts of modified 2B4 with previously published data locates the $\mathrm{v}(\mathrm{Fe}-\mathrm{CO}) / \mathrm{v}(\mathrm{C}-\mathrm{O})$ points obtained for the samples studied here (dotted line, Figure 2 inset) only slightly below the line previously derived for cytochrome P450cam samples (solid line, Figure 2 inset); the implied strongly nonpolar environment on the distal site of the heme moiety is obviously most reasonably associated with the presence of the attached apolar BPA fragment.

In summary, the acquired RR data confirm that the BPA modification of $2 \mathrm{~B} 4 \mathrm{dH}$ protein does not substantially alter the restingstate heme structure but does block the BZ substrate from entrance to the distal pocket. Most importantly, the present studies of the COligated forms convincingly demonstrate the impressive potential of RR spectroscopy to effectively document even small structural changes associated with MB inhibition, including alterations in axial-ligand disposition, heme macrocycle deformation, and variations in vinyl group orientation, changes that could potentially lead to differences in 
NOT THE PUBLISHED VERSION; this is the author's final, peer-reviewed manuscript. The published version may be accessed by following the link in the citation at the bottom of the page.

reduction potential or affinity for axial ligands and impact the stability of key peroxo and hydroperoxo intermediates.

\section{Acknowledgment}

This work was supported by grants from the National Institutes of Health (DK35153 to J.R.K. and CA16954 to P.F.H.).

\section{Supporting Information}

Active-site structure, low-frequency RR spectra of SF and BZ-bound WT P450 2B4 and the modified enzyme; and high-frequency RR spectra of CO adducts showing the vinyl stretching modes. This material is available free of charge via the Internet at http://pubs.acs.org.

\section{References}

${ }^{1}$ Metal Ions in Life Sciences; Sigel, A., Sigel, H. and Sigel, R. K. O., Eds.; John Wiley \& Sons: Chichester, U.K., 2007; Vol. 3.

${ }^{2}$ Hollenberg, P. F., Kent, U. M. and Bumpus, N. N. Chem. Res. Toxicol. 2008, 21, 189

${ }^{3}$ Biological Applications of Raman Spectroscopy; Spiro, T. G., Ed.; John Wiley \& Sons: New York, 1988.

${ }^{4} \mathrm{Hu}$, S., Schneider, A. and Kincaid, J. R. J. Am. Chem. Soc. 1991, 113, 4815

${ }^{5}$ Mak, P. J., Denisov, I. G., Victoria, D., Makris, T. M., Deng, T., Sligar, S. G. and Kincaid, J. R. J. Am. Chem. Soc. 2007, 129, 6382

${ }^{6}$ Denisov, I. G., Mak, P. J., Makris, T. M., Sligar, S. G. and Kincaid, J. R. J. Phys. Chem. A 2008, 112, 13172

7Zhang, H., Lin, H.-L., Walker, V. J., Hamdane, D. and Hollenberg, P. F. Mol. Pharmacol. 2009, 76, 1011

${ }^{8}$ Wells, A. V., Li, P., Champion, P. M., Martinis, S. A. and Sligar, S. G. Biochemistry 1992, 31, 4384

${ }^{9}$ Mak, P. J., Im, S.-C., Zhang, H., Waskell, L. A. and Kincaid, J. R. Biochemistry 2008, 47, 3950

${ }^{10}$ Uno, T., Nishimura, Y., Makino, R., Iizuka, T., Ishimura, Y. and Tsuboi, M. J. Biol. Chem. 1985, 260, 2023

11Jung, C., Hoa, G. H., Schroder, K. L., Simon, M. and Doucet, J. P. Biochemistry 1992, 31, 12855

${ }^{12} \mathrm{Hu}, \mathrm{S}$. and Kincaid, J. R. J. Am. Chem. Soc. 1991, 113, 2843

${ }^{13}$ Bangcharoenpaurpong, O. Ph.D. Dissertation, Northeastern University, Boston, MA, 1987.

${ }^{14}$ Ray, G. B., Li, X.-Y., Ibers, J. A., Sessler, J. L. and Spiro, T. G. J. Am. Chem. Soc. 1994, 116, 162

Journal of the American Chemical Society, Vol 132, No. 5 (February 2010): pg. 1494-1495. DOI. This article is (c) American Chemical Society and permission has been granted for this version to appear in e-Publications@Marquette. American Chemical Society does not grant permission for this article to be further copied/distributed or hosted elsewhere without the express permission from American Chemical Society. 
NOT THE PUBLISHED VERSION; this is the author's final, peer-reviewed manuscript. The published version may be accessed by following the link in the citation at the bottom of the page.

${ }^{15}$ Spiro, T. G. and Wasbotten, I. H. J. Inorg. Biochem. 2005, 99, 34

${ }^{16}$ Ibrahim, M., Xu, C. and Spiro, T. G. J. Am. Chem. Soc. 2006, 128, 16834

${ }^{17}$ Chen, Z., Ost, T. W. B. and Schelvis, J. P. M. Biochemistry 2004, 43, 1798

${ }^{18}$ Lee, K. B., Jun, E., La Mar, G. N., Rezzano, I. N., Pandey, R. K., Smith, K. M., Walker, F. A. and Buttlaire, D. H. J. Am. Chem. Soc. 1991, 113, 3576

${ }^{19}$ Reid, L. S., Lim, A. R. and Mauk, A. G. J. Am. Chem. Soc. 1986, 108, 8197

Journal of the American Chemical Society, Vol 132, No. 5 (February 2010): pg. 1494-1495. DOI. This article is (c) American Chemical Society and permission has been granted for this version to appear in e-Publications@Marquette. American Chemical Society does not grant permission for this article to be further copied/distributed or hosted elsewhere without the express permission from American Chemical Society. 